\title{
Organogênese do caquizeiro a partir de segmentos radiculares
}

\author{
Organogenesis of japanese persimmon from root segments
}

\author{
Dayse Cristina de Carvalho ${ }^{1}$ Luiz Antonio Biasi ${ }^{2}$
}

\section{RESUMO}

A produção de mudas de caquizeiro (Diospyros kaki) pelo processo da enxertia sobre porta-enxertos provenientes de sementes, ocasiona problemas de desuniformidade vegetativa. O objetivo do trabalho foi contribuir para o desenvolvimento de um protocolo para a regeneração de brotações de caquizeiro do tipo café, a partir de raízes por organogênese indireta. Segmentos radiculares obtidos de embrioes germinados in vitro foram

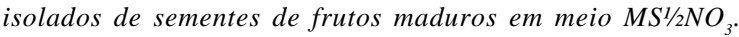
As sementes receberam assepsia pela imersão em etanol $70 \%$ por um minuto, em solução de hipoclorito de sódio $2,5 \%$ por 20 minutos e quatro lavagens em água esterilizada. No primeiro experimento, os segmentos radiculares de $2 \mathrm{~cm}$ foram isolados em meio de cultura

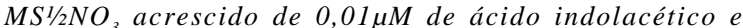
quatro tipos de citocininas nas concentrações 1 e $10 \mu \mathrm{M}$ : zeatina, 6-benzilaminopurina, 2-isopenteniladenina $e$ thidiazuron. No segundo experimento, para o enraizamento das brotações, foram testados quatro períodos de permanência em meio com 10 $\mu M$ de ácido indolbutírico: 0 , 510 e 15 dias. A maior regeneração de brotos (1,2 brotos por explante) ocorreu na combinação $1 \mu M$ de zeatina com $0,01 \mu M$ de ácido indolacético. As brotações juvenis obtidas possuem potencial natural para o enraizamento, sendo necessário novos estudos para confirmar o efeito da aplicação de auxinas.

Palavras-chave: Diospyros kaki, cultura de tecidos, micropropagação, reguladores de crescimento.

\section{ABSTRACT}

The production of japanese persimmon (Diospyros kaki) plants by grafting on seedling rootstocks results on vegetative variability problems. The goal of this work was to develop a protocol for bud regeneration using buds obtained by indirect root organogenesis. Explants were obtained by root segments of embryos germinated from mature seeds. The breeds were isolated in vitro on $\mathrm{MS}^{1 / 2} \mathrm{NO}_{3}$ medium. Seeds were sterilized by immersion in $70 \%$ ethanol for 1 min following immersion in $2.5 \%$ sodium hypochlorite for 20 min. They were then washed four times with autoclaved water. In the first experimento, root segments of $2 \mathrm{~cm}$ were isolated in $\mathrm{MS}^{1 / 2} \mathrm{NO}_{3}$ culture medium supplemented with $0.01 \mu M$ indoleacetic acid and four cytokinins (zeatin, 6benzylaminopurine, 2-isopentenyladenine and thidiazuron) at concentrations of 1 and $10 \mu \mathrm{M}$ each. The second experiment evaluated four periods in media contaning $10 \mu M$ indolebutyric acid (0, 5, 10 and 15 days) for shoot rooting. The highest bud regeneration (1.2 buds/explant) was observed when a combination of $1 \mu \mathrm{M}$ zeatin and $0.01 \mu \mathrm{M}$ indoleacetic acid was used. The juvenile buds obtained showed natural potential for rooting, but additional experiments are needed to confirm the auxin effects.

Key words: Diospyros kaki, tissue culture, growth regulators, micropropagation.

\section{INTRODUÇÃO}

A obtenção de mudas de boa qualidade para a implantação de pomares constitui-se em sério problema para os fruticultores que pretendem cultivar o caquizeiro (Diospyros kaki) (BIASI et al., 1999). Este fato é influenciado pela propagação dos portaenxertos por sementes de outros caquizeiros. A heterozigosidade resulta em grande desuniformidade quanto ao porte e vigor das plantas, ocasionando a formação de pomares heterogêneos (MARTINS \& PEREIRA, 1989; FUKUI et al., 1989; CHOI et al., 2001). Além disso, o caquizeiro apresenta grande dificuldade de enraizamento por meio de estacas caulinares (TAO \& SUGIURA, 1992), restringindo ainda mais as formas de obtenção de mudas por propagação vegetativa em larga escala.

A solução para este problema requer avanços na pesquisa de forma a gerar novas

\footnotetext{
${ }^{1}$ Engenheiro Agrônomo, MSc, Aluno do Programa de Pós-graduação em Agronomia, Escola Superior de Agricultura "Luiz de Queiroz”, Universidade de São Paulo. E-mail: dayse@esalq.usp.br.

${ }^{2}$ Professor Adjunto, Universidade Federal do Paraná, CP 19061, 81531-990, Curitiba, PR. E-mail: biasi@ufpr.br. Bolsista de Produtividade em Pesquisa do Conselho Nacional de Desenvolvimento Científico e Tecnológico (CNPq).
} 
tecnologias para a propagação vegetativa que permitam a formação direta de mudas a partir das cultivares de interesse, representando um avanço significativo para a cultura do caquizeiro (MARTINS \& PEREIRA, 1989). Métodos para a micropropagação do caquizeiro têm sido desenvolvidos, todavia, sua aplicação para a produção comercial de mudas tem sido limitada porque as microestacas de caquizeiro geralmente são difíceis de enraizar(TAO \& SUGIURA, 1992).

A regeneração de plantas via organogênese indireta já foi alcançada utilizando hipocótilos de plantas germinadas in vitro (YOKOYAMA \& TAKEUCHI, 1976; YAMADA et al., 1987), anteras (TAO et al., 1992), segmentos internodais e folhas jovens (TAO \& SUGIURA, 1992) e também a partir de primórdios foliares de gemas dormentes (TAO et al., 1988). TETSUMURA \& YUKINAGA (1996) realizaram o trabalho pioneiro de organogênese a partir de raízes de caquizeiro, obtendo a regeneração de brotos em alta freqüência (85\% dos explantes). TAMURA et al. (1992) relacionaram este fato a juvenilidade dos tecidos radiculares. Segundo BONGA (1982), se a juvenilidade for conservada nas brotações regeneradas, estas podem ser facilmente enraizadas e micropropagadas.

Os trabalhos com a cultura de tecidos do caquizeiro são relativamente recentes e a maioria deles foram realizados em universidades japonesas. No Brasil, as pesquisas com cultura de tecidos de caquizeiro apresentam resultados bastante promissores para a clonagem da espécie e a solução dos problemas mencionados anteriormente (BIASI et al., 1999; SALOMÃO et al., 2000).

Este trabalho foi realizado com o objetivo de contribuir para o estabelecimento de um protocolo de propagação in vitro do caquizeiro por organogênese a partir de segmentos radiculares.

\section{MATERIAL E MÉTODOS}

Os experimentos foram conduzidos no Laboratório de Micropropagação de Plantas do Departamento de Fitotecnia e Fitossanitarismo da Universidade Federal do Paraná (UFPR) entre 2001 e 2002. Como fonte de explantes foram utilizadas sementes extraídas de frutos maduros de caquizeiro do tipo café, as quais receberam assepsia pela imersão em etanol $70 \%$ por um minuto, hipoclorito de sódio 2,5\% por 20 minutos e quatro lavagens em água esterilizada. Em câmara de fluxo laminar as sementes foram abertas, os embriões extraídos e colocados em frascos individuais de $50 \mathrm{ml}$ contendo $10 \mathrm{ml}$ de meio de cultura $\mathrm{MS}^{1} / 2 \mathrm{NO}_{3}(\mathrm{MURASHIGE} \& \mathrm{SKOOG}$ 1962) com a metade da concentração de nitratos, para sua germinação e solidificado com $6 \mathrm{gL}^{-1}$ de ágar. Quando as plântulas apresentavam pelo menos $5 \mathrm{~cm}$ de comprimento radicular, as raízes foram utilizadas como fonte de explantes para os dois experimentos de organogênese.

Os frascos foram mantidos em sala de crescimento com temperatura de $25 \pm 2^{\circ} \mathrm{C}$, fotoperíodo de 16 horas e intensidade luminosa média de $25 \mu \mathrm{molm}^{-2} \mathrm{~s}^{-1}$, fornecida por lâmpadas fluorescentes do tipo luz do dia.

Experimento 1 - Efeito de reguladores de crescimento na indução de brotações adventícias

Segmentos radiculares com aproximadamente $2 \mathrm{~cm}$ de comprimento foram isolados em meio de cultura $\mathrm{MS} 1 / 2 \mathrm{NO}_{3}$ acrescido de $0,01 \mu \mathrm{M}$ de AIA (ácido indolacético) e quatro tipos de citocininas: zeatina, BAP (6-benzilaminopurina), 2-iP (2isopenteniladenina) e TDZ (thidiazuron), nas concentrações 1 e $10 \mu \mathrm{M}$. O delineamento experimental foi em blocos ao acaso com quatro repetições e 15 explantes por parcela. Os explantes foram isolados em frascos de $250 \mathrm{ml}$ contendo $30 \mathrm{ml}$ de meio de cultura, sendo colocados cinco explantes por frasco. A avaliação foi realizada após 90 dias da instalação do experimento, sendo determinados a percentagem de explantes com calo, percentagem de explantes com brotação, número de brotos maiores e menores que um centímetro (por explante) e percentagem de explantes com folhas.

\section{Experimento 2 - Enraizamento das brotações}

Brotações com tamanho superior a $1 \mathrm{~cm}$ e pelo menos uma folha expandida foram utilizadas, testando-se o tempo de permanência $(0,5,10$ e 15 dias $)$ em meio de cultura $\mathrm{MS}^{1} / 2 \mathrm{NO}_{3}$ com $10 \mu \mathrm{M}$ de AIB (ácido indolbutírico) e posterior transferência para meio sem reguladores de crescimento e com $1 \mathrm{gL}^{-1}$ de carvão ativado. O delineamento experimental foi em blocos ao acaso com quatro repetições e dez explantes por parcela. Os explantes foram isolados em frascos de $250 \mathrm{ml}$ contendo $30 \mathrm{ml}$ de meio de cultura, sendo colocados cinco explantes por frasco. Após 30 dias da instalação avaliaram-se a percentagem de brotações enraizadas, comprimento das raízes e número de raízes por brotação.

\section{RESULTADOS E DISCUSSÃO}

Experimento 1 - Efeito de reguladores de crescimento na indução de brotações adventícias

Todas as citocininas testadas induziram a formação de brotações a partir dos segmentos 
radiculares (Tabela 1). Quando não havia citocinina no meio de cultura, a formação de brotações adventícias não ocorreu. Este resultado indica a dependência de citocininas para o cultivo inicial de segmentos radiculares de caquizeiro, similarmente ao cultivo de ápices meristemáticos, relatado por BIASI et al. (1999). Comparando os vários tipos de citocininas em todas as concentrações, combinadas com $0,01 \mu \mathrm{M}$ de AIA, o melhor resultado, em termos de percentagem de explantes que formaram brotações, foi encontrado com $1 \mu \mathrm{M}$ de zeatina, embora este tratamento não tenha sido superior isoladamente. Brotações foram regeneradas a partir de raízes de quatro diferentes cultivares de caquizeiro em meio suplementado com $0,01 \mu \mathrm{M}$ de AIA e $10 \mu \mathrm{M}$ de zeatina (TETSUMURA \& YUKINAGA, 2000).

A regeneração de gemas também foi obtida a partir de segmentos foliares cultivados em meio $\mathrm{MS}^{1} / 2 \mathrm{NO}_{3}$ suplementado com $0,1 \mathrm{mgL}^{-1}$ de AIB e $10 \mathrm{mgL}^{-1}$ de zeatina (CHOI et al., 2001). A concentração $10 \mu \mathrm{M}$ de zeatina foi definida para o cultivo de ápices meristemáticos de caquizeiro por TAO \& SUGIURA (1992) e BIASI et al. (1999). No entanto, no presente trabalho a concentração mais efetiva para a organogênese de segmentos radiculares foi mais baixa $(1 \mu \mathrm{M}$ de zeatina). Isto pode ter ocorrido devido à juvenilidade dos tecidos radiculares, pois segundo TAMURA et al. (1992) há maior sucesso, nos protocolos de organogênese in vitro, se forem utilizados tecidos juvenis, que possuem maior competência organogênica, como ápices radiculares.

No presente trabalho, a concentração de $10 \mu \mathrm{M}$ de zeatina diferiu significativamente da concentração de $1 \mu \mathrm{M}$ apenas para a variável percentagem de explantes com calos. As mais elevadas porcentagens de formação de calos ocorreram com a aplicação de zeatina e TDZ, ambos na concentração de $10 \mu \mathrm{M}$, que também apresentaram menor porcentagem de explantes com brotações. Isso revelou que a concentração de $10 \mu \mathrm{M}$ foi muito elevada, induzindo uma proliferação excessiva de calos em detrimento da organogênese. O 2-iP apresentou fraco efeito na formação de calos e brotações, mesmo na concentração de $10 \mu \mathrm{M}$, induzindo poucos brotos muito pequenos e sem expansão foliar (Figura 1).

No cultivo in vitro de ápices meristemáticos de caquizeiro, a ocorrência de calos pode atingir até $60 \%$ em meio de cultura Gamborg suplementado com 10 a $20 \mu \mathrm{M}$ de zeatina e essa excessiva formação de calo pode inibir a proliferação de brotações (SUGIURA et al., 1986; FUKUI et al., 1989; FUKUI et al., 1990).

A zeatina na concentração de $1 \mu \mathrm{M}$ induziu a formação de maior número de brotações tanto menores quanto maiores de $1 \mathrm{~cm}$. O TDZ, analogamente a $10 \mu \mathrm{M}$ de zeatina, atuou na formação de calos (Figura 1). O TDZ tem sido amplamente utilizado na micropropagação por ser um excelente estimulante para a formação de calos em concentrações iguais ou maiores que $1 \mu \mathrm{M}$ (HUETTEMAN \& PREECE, 1993).

A formação de brotações adventícias é dependente do fator genético de cada cultivar de caquizeiro (CHOI et al., 2001). A cultivar Fuyu, comercialmente muito importante, mostrou resistência a respostas regenerativas e provou ser recalcitrante. Todavia, a zeatina é especialmente efetiva para o cultivo in vitro do caquizeiro, mas sua utilização na produção de mudas pode gerar custos muito elevados. Então, se a micropropagação puder ser realizada com uma citocinina de menor custo, a zeatina deve ser evitada (FUKUI et al., 1990; TAO \& SUGIURA, 1992). Nesse trabalho os resultados obtidos com $1 \mu \mathrm{M}$ de TDZ foram

Tabela 1 - Efeito das citocininas 6-benzilaminopurina (BAP), thidiazuron (TDZ), 2-isopenteniladenina (2-iP) e zeatina nas concentrações de 1 e $10 \mu \mathrm{M}$, associadas à auxina ácido indolacético (AIA) $0,01 \mu \mathrm{M}$, sobre o desenvolvimento organogênico de segmentos radiculares de caquizeiro do tipo café. UFPR, Curitiba, 2002.

\begin{tabular}{|c|c|c|c|c|c|}
\hline Citocinina & $\begin{array}{l}\text { Explantes com } \\
\text { calo }(\%)^{1}\end{array}$ & $\begin{array}{l}\text { Explantes com } \\
\text { brotação }(\%)^{1}\end{array}$ & $\begin{array}{c}\text { Brotos < } \\
1 \mathrm{~cm} / \text { explante }^{1}\end{array}$ & $\begin{array}{c}\text { Brotos > } \\
1 \mathrm{~cm} / \text { explante }\end{array}$ & $\begin{array}{l}\text { Explantes com } \\
\text { folhas }(\%)^{1}\end{array}$ \\
\hline Zeatina $1 \mu \mathrm{M}$ & $5,2 \mathrm{bc}^{2}$ & $44,3 \mathrm{a}$ & $0,8 \mathrm{a}$ & $0,4 \mathrm{a}$ & $25,8 \mathrm{a}$ \\
\hline Zeatina $10 \mu \mathrm{M}$ & $48,1 \mathrm{ab}$ & $33,0 \mathrm{ab}$ & $0,7 \mathrm{ab}$ & $0,1 \mathrm{ab}$ & $5,2 \mathrm{ab}$ \\
\hline BAP $1 \mu \mathrm{M}$ & $0,0 \mathrm{c}$ & $1,4 \mathrm{bc}$ & $0,0 \mathrm{~b}$ & $0,0 \mathrm{~b}$ & $1,4 \mathrm{ab}$ \\
\hline BAP $10 \mu \mathrm{M}$ & $7,6 \mathrm{abc}$ & $17,5 \mathrm{abc}$ & $0,2 \mathrm{ab}$ & $0,1 \mathrm{ab}$ & $5,2 \mathrm{ab}$ \\
\hline 2 -iP $1 \mu \mathrm{M}$ & $2,9 \mathrm{c}$ & $0,8 \mathrm{c}$ & $0,0 \mathrm{~b}$ & $0,0 \mathrm{~b}$ & $0,0 \mathrm{~b}$ \\
\hline 2 -iP $10 \mu \mathrm{M}$ & $2,9 \mathrm{c}$ & $12,9 \mathrm{abc}$ & $0,1 \mathrm{ab}$ & $0,0 \mathrm{~b}$ & $0,0 \mathrm{~b}$ \\
\hline $\mathrm{TDZ} 1 \mu \mathrm{M}$ & $14,9 \mathrm{abc}$ & $31,8 \mathrm{ab}$ & $0,7 \mathrm{ab}$ & $0,1 \mathrm{~b}$ & $15,0 \mathrm{ab}$ \\
\hline TDZ $10 \mu \mathrm{M}$ & $52,3 \mathrm{a}$ & $2,9 \mathrm{bc}$ & $0,1 \mathrm{ab}$ & $0,0 \mathrm{~b}$ & $0,0 \mathrm{~b}$ \\
\hline TESTEMUNHA & $0,0 \mathrm{c}$ & $0,0 \mathrm{c}$ & $0,0 \mathrm{~b}$ & $0,0 \mathrm{~b}$ & $0,0 \mathrm{~b}$ \\
\hline $\mathrm{CV}(\%)$ & 34,96 & 23,92 & 35,53 & 41,58 & 23,35 \\
\hline
\end{tabular}

${ }^{1}$ Dados transformados em arco seno da raiz $(\mathrm{x} / 100)$

${ }^{2}$ Médias seguidas por letras distintas nas colunas diferem entre si pelo teste de Tukey a 5\% de probabilidade de erro. 


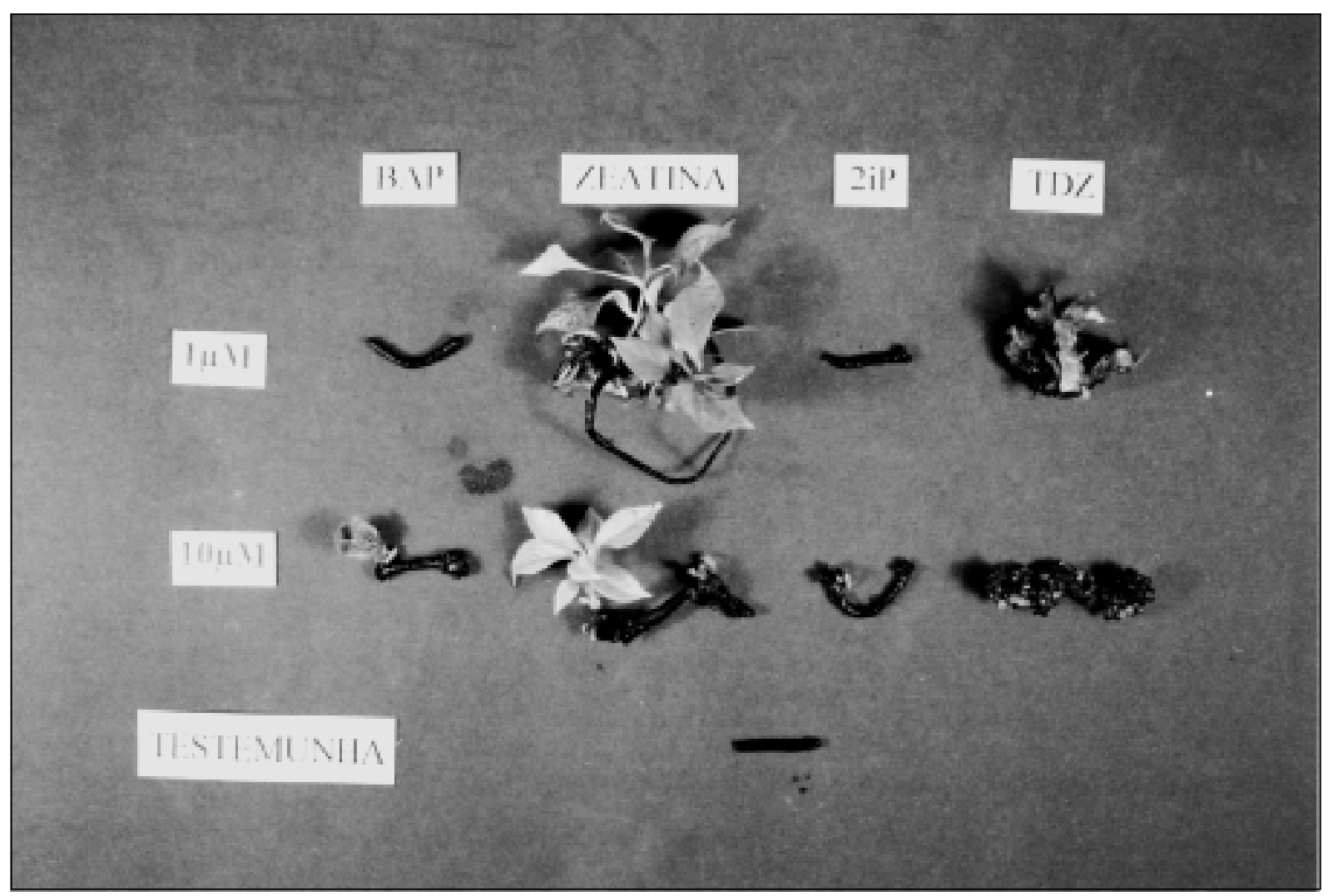

Figura 1 - Aspecto da resposta organogênica de segmentos radiculares de caquizeiro do tipo café, a aplicação das citocininas 6benzilaminopurina (BAP), thidiazuron (TDZ), 2-isopenteniladenina (2-iP) e zeatina nas concentrações de 1 e $10 \mu \mathrm{M}$, associadas à auxina ácido indolacético (AIA) $0,01 \mu \mathrm{M}$. UFPR, Curitiba, 2002

próximos aos obtidos com $10 \mu \mathrm{M}$ de zeatina, indicando que esse regulador deve ser melhor estudado por ser efetivo e mais econômico do que a zeatina.

Níveis reduzidos de TDZ e muitos outros compostos de feniluréia-piridil têm demonstrado estimular a formação de meristemas e gemas in vitro. Esses compostos têm apresentado os mesmos efeitos das citocininas para muitas espécies (FELLMAN et al., 1987). O TDZ tem tornado viável a micropropagação de muitas espécies recalcitrantes. Baixas concentrações de TDZ $(<1 \mu \mathrm{M})$ podem induzir maior proliferação de gemas axilares, quando comparadas com outras substâncias com atividade citocinínica, no entanto, pode inibir o alongamento das brotações (HUETTEMAN \& PREECE, 1993). Sugere-se, pelo custo do TDZ ser menor do que a zeatina, maiores investigações quanto ao seu efeito na formação de brotações adventícias, empregando concentrações mais reduzidas deste fitorregulador ou diferentes formas de tratamento dos explantes, como imersão em "solução-pulso" (de elevada concentração) de TDZ e posterior isolamento do tecido em meio livre de reguladores de crescimento.
Experimento 2 - Enraizamento das brotações

Não houve diferença significativa entre os períodos de permanência das brotações em meio suplementado com 10 $\mu \mathrm{M}$ de AIB (Tabela 2). Observou-se, porém, maior tendência à emissão de raízes e maior vigor da parte aérea e radicular quando os explantes foram tratados com AIB por um período mais prolongado em meio auxínico (Figura 2).

Tabela 2 - Efeito do período de permanência em meio de cultura com $10 \mu \mathrm{M}$ de ácido indolbutírico (AIB), no enraizamento das brotações de caquizeiro do tipo café. UFPR, Curitiba, 2002.

\begin{tabular}{cccc}
\hline Dias & $\begin{array}{c}\text { Brotações } \\
\text { enraizadas (\%) }\end{array}$ & $\begin{array}{c}\text { Comprimento } \\
\text { das raízes (cm) }\end{array}$ & $\begin{array}{c}\text { Número de raízes } \\
\text { por brotação }\end{array}$ \\
\hline 0 & $34,37^{\mathrm{NS}}$ & $2,90^{\mathrm{NS}}$ & $2,00^{\mathrm{NS}}$ \\
5 & 62,50 & 4,23 & 2,87 \\
10 & 53,12 & 3,44 & 2,62 \\
15 & 71,87 & 4,24 & 3,22 \\
$\mathrm{CV}(\%)$ & 55,88 & 24,89 & 24,03 \\
\hline
\end{tabular}

${ }^{1}$ Dados originais transformados em arco seno da raiz $(\mathrm{x} / 100)$

${ }^{2}$ Dados originais transformados em raiz $(x+1)$

${ }^{\mathrm{NS}}$ As médias não diferiram significativamente pelo teste $\mathrm{F}$ da análise de variância. 


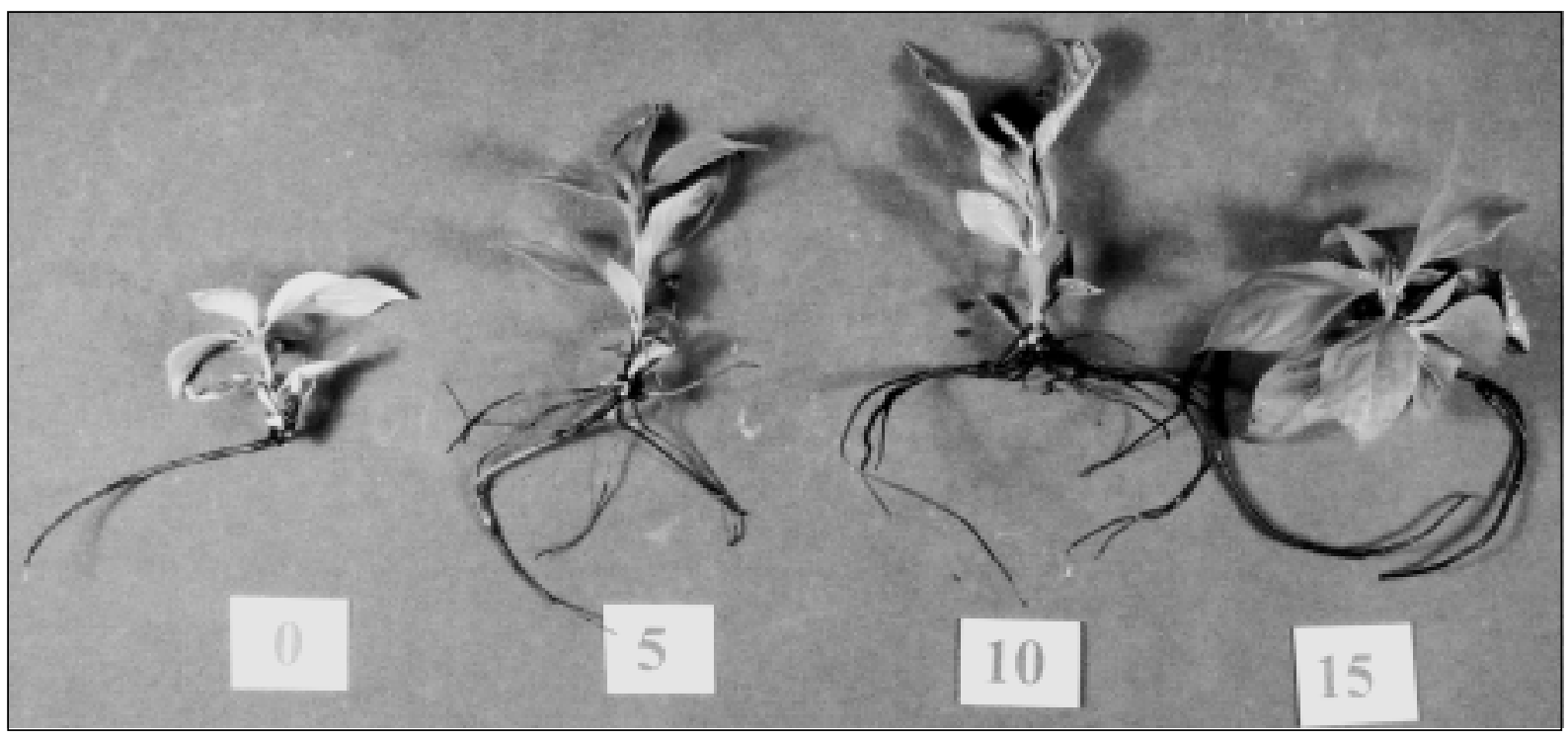

Figura 2 - Aspecto da resposta de enraizamento das brotações de caquizeiro do tipo café em função do período de permanência em meio

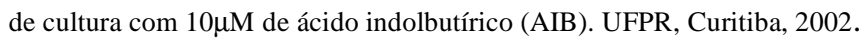

Por outro lado, pode-se constatar um potencial natural das brotações regeneradas de raízes para o enraizamento, sem que haja requerimento de reguladores de crescimento. Esta facilidade para o enraizamento pode estar associada à retenção da juvenilidade dos explantes, observada em plantas regeneradas in vitro (TETSUMURA \& YUKINAGA, 1996). Brotações adventícias produzidas a partir de raízes tendem a ser juvenis, logo, podem ser facilmente enraizadas e micropropagadas (BONGA, 1982).

A capacidade para enraizamento in vitro é muito variável dentre as cultivares de caquizeiro (TAO \& SUGIURA, 1992). Um experimento com 95 cultivares revelou que apenas 16 possuem elevado potencial de enraizamento (acima de 70\%) quando tratadas com ANA, aplicado na forma de talco a 40\% (FUKUI et al., 1992).

Brotações regeneradas de ápices meristemáticos da cultivar Hiratanenashi apresentaram $96 \%$ de enraizamento, enquanto da cultivar Kurogashi apenas $8 \%$, em meio suplementado com $250 \mathrm{mgL}^{-1} \mathrm{de}$ AIB (MURAYAMA et al., 1989). Com a cultivar Fuyu não foi obtida nenhuma microestaca enraizada em meio com $1 \mu \mathrm{M}$ de AIB, observando-se ainda efeitos negativos sobre os explantes, como a oxidação e formação de calos (BIASI et al., 1999).

As percentagens de enraizamento de brotações regeneradas a partir de raízes de três cultivares de caquizeiro foram maiores do que aquelas obtidas em brotações provenientes do cultivo de ápices meristemáticos. As brotações obtidas pela organogênese em raízes da cultivar Jirô enraizaram dez dias mais cedo e com maior número de raízes do que as brotações regeneradas de ápices meristemáticos (TETSUMURA \& YUKINAGA, 2000). O alto grau de enraizamento em estacas juvenis é devido à elevada concentração de níveis endógenos de auxina que as estacas juvenis tipicamente contêm ou devido à grande sensibilidade nestes tecidos (ARTECA, 1995).

\section{CONCLUSÕES}

A micropropagação do caquizeiro pela organogênese indireta em segmentos radiculares pode ser obtida pelo cultivo destes em meio de cultura MS com a metade da concentração dos nitratos suplementado com $1 \mu \mathrm{M}$ de zeatina e $0,01 \mu \mathrm{M}$ de ácido indolacético. As brotações juvenis obtidas possuem potencial natural para o enraizamento, sendo necessário novos estudos para confirmar o efeito da aplicação de auxinas.

\section{REFERÊNCIAS BIBLIOGRÁFICAS}

ARTECA, R.N. Plant growth substances: principles and applications. Pennsylvania : Chapman \& Hall, 1995. 332p.

BIASI, L.A. et al. Estabelecimento in vitro do caquizeiro 'Fuyu' por meio de ápices meristemáticos. Revista Brasileira de Fruticultura, Jaboticabal, v.21, n.3, p.279-283, 1999.

BONGA, J.M. Vegetative propagation in relation to juvenility, maturity and rejuvenation. In: BONGA, J.M.; DURZAN, D.J. 
Tissue culture in forestry. Netherlands : Martinus Nijhoff, The Hague, 1982. p.387-412.

CHOI, J.Y et al. Efficient and simple plant regeneration via organogenesis from leaf segment cultures of persimmon (Diospyros kaki Thunb). In Vitro Celular and Developmental Biology Plant, v.37, n.2, p.274-179, 2001.

FELLMAN, C.D.; READ, P.E.; HOSIER, M.A. Effects of thidiazuron and CPPU on meristem formation and shoot proliferation. Hortscience, v.22, n.6, p.1197$1200,1987$.

FUKUI, H. et al. Annual changes in responsiveness of shoot tip cultures to cytokinin in Japanese Persimmon. Journal of the Japanese Society for Horticultural Science, v.59, n.2, p.271-274, 1990.

FUKUI, H.; NISHIMOTO, K.; NAKAMURA, M. Varietal differences in rooting ability of in vitro subcultures Japanese Persimmon shoots. Journal of the Japanese Society for Horticultural Science, v.60, n.4, p.821-825, 1992.

FUKUI, H.; SUGIYAMA, M.; NAKAMURA, M. Shoot tip culture of Japanese Persimmon (Diospyros kaki L.). Journal of the Japanese Society for Horticultural Science, v.58, p.43-47, 1989.

HUETTEMAN, C.A.; PREECE, J.E. Thidiazuron: a potent cytokinin for wood plant tissue culture. Plant Cell, Tissue and Organ Culture, v.33, n.2, p.105-119, 1993.

MARTINS, F.P.; PEREIRA, F.M. Cultura do caquizeiro. Jaboticabal : FUNEP, 1989. 71p.

MURAYAMA, $H$. et al. In vitro shoot proliferation and rooting of several Japanese Persimmon cultivars. Journal of the Japanese Society for Horticultural Science, v.58, n.1, p.55-61, 1989.

SALOMÃO, L.C.C. et al. Micropropagação de caquizeiro 'Cereja' por meio de gemas apicais e laterais de plantas juvenis e adultas. Revista Brasileira de Fruticultura, Cruz das Almas, v.22, n.1, p.66-71, 2000.

SUGIURA, A. et al. In vitro propagation of Japanese persimmon. HortScience, v.21, n.5, p.1205-1207, 1986.

TAMURA, M.; TAO, R.; SUGIURA, A. Highly stable regeneration from long-term cultures of Japanese persimmon callus. HortScience, v.27, n.9, p.1048. 1992.

TAO, R.; ITO, J.; SUGIURA, A. Adventitious bud formation on callus derived from anthers of persimmon 'Meotogaki' and isozyme variations observed in the regenerated plantlets. Journal of the Japanese Society for Horticultural Science, v.61, n.3, p.527-533, 1992.

TAO, R. et al. Plant regeneration from callus cultures derived from primordial leaves of adult Japanese persimmon. HortScience, v.23, n.6, p.1055-1056, 1988.

TAO, R.; SUGIURA, A. Micropropagation of Japanese persimmon (Diospyros kaki L.). In: BAJAJ, Y.P.S. (Ed.). Biotechnology in agriculture and forestry. High-Tech and Micropropagation II. Berlin: Springer-Verlag, 1992. V. 18 , cap. 11 , p.423-440.

TETSUMURA, T.; YUKINAGA, H. Comparative rooting of shoot tips of four Japanese persimmon cultivars vs. shoots regenerated from roots cultured in vitro. HortScience, v.35, n.5, p.940-944, 2000.

TETSUMURA, T.; YUKINAGA, H. High-frequency shoot regeneration from roots of Japanese persimmon. HortScience, v.31, n.3, p.463-464, 1996.

YAMADA, K.; MATSUMOTO, T; HARUKI, K. Adventitious bud formation from hypocotyl segments in seed of Japanese persimmon. Journal of the Japanese Society for Horticultural Science, v.64, n.2, p.154-155, 1987.

YOKOYAMA, T.; TAKEUCHI, M. Organ and plantlet formation from callus in Japanese persimmon (Diospyros kaki). Phytomorphology, v.26, p.273-275, 1976. 